\title{
Effect of calcination temperatures on the photocatalytic activities of commercial titania nanoparticles under solar simulator irradiation
}

\author{
Wai Ruu Siah ${ }^{1}$, Hendrik O. Lintang ${ }^{1}$, Mustaffa Shamsuddin ${ }^{2}$ and Leny Yuliati ${ }^{1 *}$ \\ ${ }^{1}$ Centre for Sustainable Nanomaterials, Ibnu Sina Institute for Scientific and Industrial Research, Universiti Teknologi Malaysia, 81310 UTM Johor Bahru, \\ Johor, Malaysia. \\ ${ }^{2}$ Department of Chemistry, Faculty of Science, Universiti Teknologi Malaysia, 81310 UTM Johor Bahru, Johor, Malaysia. \\ "Corresponding Author: leny@ibnusina.utm.my
}

Article history :

Received 31 October 2015

Accepted 15 November 2015

\section{GRAPHICAL ABSTRACT}

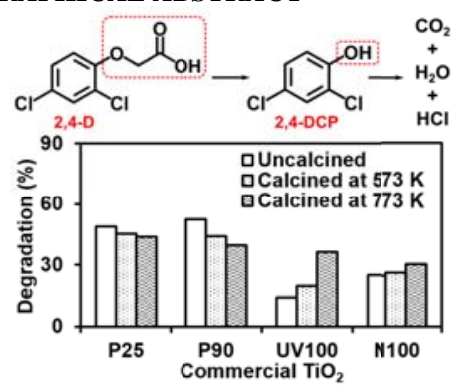

\section{ABSTRACT}

In this study, the effect of calcination temperatures on the photocatalytic activity of commercial $\mathrm{TiO}_{2}$ photocatalysts (Evonik P25, Evonik P90, Hombikat UV100, Hombikat N100) was evaluated for degradation and removal of 2,4-dichlorophenoxyacetic acid (2,4-D) herbicide under solar simulator irradiation. The calcined samples were prepared by heating commercial $\mathrm{TiO}_{2}$ photocatalysts at 573 or $773 \mathrm{~K}$ for 4 hours. It was confirmed that before calcination treatment, the $\mathrm{P}_{25} \mathrm{TiO}_{2}$ showed similar activity to the $\mathrm{P} 90 \mathrm{TiO}_{2}$, which activity was higher than those of Hombikat UV100 and $\mathrm{N} 100 \mathrm{TiO}_{2}$. The activity of P25 and P90 was reduced when the photocatalysts were calcined at $573 \mathrm{~K}$ and $773 \mathrm{~K}$. On the other hand, the Hombikat catalysts showed an improved activity with the increase of calcination temperatures.

Keywords: commercial $\mathrm{TiO}_{2}$ nanoparticles, calcination temperature, 2,4-dichlorophenoxyacetic acid, solar simulator

\section{INTRODUCTION}

The widespread disposal of agricultural, industrial and domestic wastewater containing various organic pollutants has led to serious contamination in many countries worldwide. Heterogeneous photocatalysis is a promising technology for water purification, whereby organic pollutants are totally degraded to carbon dioxide and water over primarily $\mathrm{TiO}_{2}$ photocatalysts. As a photocatalyst, $\mathrm{TiO}_{2}$ has a range of useful features, including high photocatalytic activity, stability, low toxicity, ready availability and low cost $[1,2]$. These features cause $\mathrm{TiO}_{2}$ to be an excellent material to mineralize a variety of organic pollutants by photooxidation.

Currently, a wide range of commercial $\mathrm{TiO}_{2}$ photocatalysts are available in the market. Due to the different methods of synthesis, the resultant commercial $\mathrm{TiO}_{2}$ generally display varying photocatalytic activity and physical properties, such as crystallinity, surface morphology and phase composition. Among various commercially available $\mathrm{TiO}_{2}$ materials, P25 generally displays the highest activity for most photocatalytic reactions. It is made up of approximately $80: 20 \%$ anataserutile phase composition, with a specific surface area (SSA) of about $50 \mathrm{~m}^{2} / \mathrm{g}$ and particle size of $\sim 20-30 \mathrm{~nm}$. On the other hand, Hombikat UV100 is another commonly used commercial $\mathrm{TiO}_{2}$, which is made up of pure anatase. It has a much larger SSA, typically larger than $200 \mathrm{~m}^{2} / \mathrm{g}$ and particle size below $\sim 10 \mathrm{~nm}[3]$.

Numerous studies have been carried out to investigate the photocatalytic activities of the $\mathrm{TiO}_{2}$ photocatalysts, especially for removal of organic pollutants. Among the commercially available $\mathrm{TiO}_{2}$, Evonik P25 [3-8] and Hombikat UV100 [3,4,9,10] have been intensively studied for various applications. However, the effect of calcination treatment on the activity of these commercial $\mathrm{TiO}_{2}$ is still unclear. For instance, it was reported that the calcined $\mathrm{P} 25 \mathrm{TiO}_{2}$ at $773 \mathrm{~K}$ showed two times higher activity than the untreated one for decolorization of methyl orange [5]. In contrast, the activity of $\mathrm{P} 25 \mathrm{TiO}_{2}$ was found to decrease with the increase of the calcination temperatures for decomposition and reduction reactions of NO [6], photodegradation of light hydrocarbons mixture [7], butanol [4] and rhodamine B dye [8]. 
Near the earth, the sun emits $0.2-0.3$ mol photons $\mathrm{m}^{-2} \mathrm{~h}^{-1}$ in the range $300-400 \mathrm{~nm}$ with a typical flux of 20 $30 \mathrm{~W} \mathrm{~m}^{-2}$. Hence, the sunlight could act as an economic and inexhaustible light source for photocatalytic degradation reactions [11]. While UV light has demonstrated promising results for the degradation of persistent organic pollutants, it is also of interest to investigate the performance of the commercial $\mathrm{TiO}_{2}$ samples under solar irradiation conditions.

Hence, in the present study, the effect of calcination temperatures on the activity of four types of commercial $\mathrm{TiO}_{2}$ (Evonik P25, Evonik P90, Hombikat UV100 and Hombikat N100) was examined under solar simulator irradiation. The selected model pollutant used for this study is 2,4-dichlorophenoxyacetic acid (2,4-D). While 2,4-D is widely used as a herbicide, it has been categorized as a drinking water contaminant as it is toxic, hardly biodegradable and difficult to remove from the environment [12].

\section{EXPERIMENTS}

\subsection{Materials}

Commercial $\mathrm{P} 25 \mathrm{TiO}_{2}$ and $\mathrm{P} 90 \mathrm{TiO}_{2}$ were obtained from Evonik Industries. Commercial Hombikat UV100 $\mathrm{TiO}_{2}$ and Hombikat $\mathrm{N} 100 \quad \mathrm{TiO}_{2}$ were obtained from Sachtleben Chemie. All $\mathrm{TiO}_{2}$ samples were used as received without any pre-treatments. The 2,4dichlorophenoxyacetic acid $\left(\mathrm{C}_{8} \mathrm{H}_{6} \mathrm{Cl}_{2} \mathrm{O}_{3}, \geq 98 \%\right)$ was purchased from Sigma.

\subsection{Preparation and Characterization of Calcined Photocatalysts}

In order to investigate the effect of the calcination temperatures, $1.0 \mathrm{~g}$ of each commercial $\mathrm{TiO}_{2}$ was subjected to calcination using a muffle furnace in air at 573 or $773 \mathrm{~K}$ for 4 hours at a heating rate of $10^{\circ} \mathrm{C} / \mathrm{min}$. After the thermal treatment, the calcined samples were allowed to cool to room temperature. Then, the samples were ground with mortar and pestle and stored under ambient conditions. Diffraction patterns of the samples were collected by an Xray diffractometer (XRD; Bruker D8 Advance diffractometer) and the crystallite size of the samples were determined from the full width half maximum (FWHM) of anatase (101) reflection at $2 \theta=25.3^{\circ}$ by a Scherrer equation.

\subsection{Photocatalytic activity tests}

The model pollutant used for photocatalytic testings was 2,4-D herbicide. The uncalcined and calcined commercial $\mathrm{TiO}_{2}$ samples $(50 \mathrm{mg})$ were first dispersed in $50 \mathrm{~mL}$ of the pollutant solution $(0.5 \mathrm{mM})$. The mixture was then stirred in the dark for 1 hour to achieve adsorptiondesorption equilibrium. While under constant stirring, the mixture was then exposed for 3 hours to a solar simulator (Peccell Technologies) equipped with a $150 \mathrm{~W}$ xenon short arc lamp. All reactions were made open to air in order to provide sufficient oxygen for the oxidative degradation of the pollutants. Upon the completion of lamp exposure, about $3 \mathrm{~mL}$ of suspension was removed and filtered using a $0.2 \mu \mathrm{m}$ nylon membrane filter. The concentration of 2,4-D before and after solar simulator irradiation and the concentration of 2,4-DCP intermediate formed was determined by a high performance liquid chromatography (HPLC, Shimadzu Prominence LC-20A) equipped with a $150 \times 4.6 \mathrm{~mm}$ Hypersil GOLD PFP column and the eluent was a mixture of acetonitrile/ $\mathrm{H}_{2} \mathrm{O} 60: 40(\mathrm{v} / \mathrm{v})$, whereby the concentration of 2,4-D and 2,4-DCP were monitored at 283 $\mathrm{nm}$. The percentage of 2,4-D degradation was determined by equation (1):

Degradation of 2,4-D $(\%)=\frac{[2,4-\mathrm{D}]_{\mathrm{I}}-[2,4-\mathrm{D}]_{\mathrm{F}}-[2,4-\mathrm{DCP}]_{\mathrm{F}}}{[2,4-\mathrm{D}]_{\mathrm{I}}} \times 100$

where $[2,4-D]_{I}$ is the initial concentration of 2,4-D pollutant, $[2,4-\mathrm{D}]_{\mathrm{F}}$ is the final concentration of $2,4-\mathrm{D}$ pollutant after lamp exposure and $[2,4-\mathrm{DCP}]_{\mathrm{F}}$ is the final concentration of the formed 2,4-DCP intermediate. On the other hand, the removal of the 2,4-D pollutant was determined by equation (2):

$$
\text { Removal of 2,4-D }(\%)=\frac{[2,4-\mathrm{D}]_{\mathrm{I}}-[2,4-\mathrm{D}]_{\mathrm{F}}}{[2,4-\mathrm{D}]_{\mathrm{I}}} \times 100
$$

\section{RESULTS AND DISCUSSION}

The uncalcined and calcined samples were characterized by XRD and the crystallite sizes were determined by the Scherrer equation. As shown in Figure 1, the crystallite size of all commercial $\mathrm{TiO}_{2}$ samples increased with the increase of the calcination temperature. The UV100 showed the most remarkable change with average crystallite size of $c a .9-16 \mathrm{~nm}$, while N100 was the least unaffected with average crystallite size of $c a .17-18$ $\mathrm{nm}$. The crystallite sizes of the P25 and the P90 were also increased, which were in the range of $c a .18-21$ and $c a .10-$ $15 \mathrm{~nm}$, respectively.

The photocatalytic activity of the commercial catalysts investigated in this study were tested by using 2,4$\mathrm{D}$ as the test pollutant. Control experiments showed that no degradation of 2,4-D was observed in the absence of photocatalyst or light. On the other hand, in the presence of both photocatalyst and solar simulator irradiation, HPLC results confirmed the degradation of 2,4-D. Before solar simulator irradiation, the HPLC spectrum only consist of one peak, which was the 2,4-D peak. After exposure to the solar simulator for 3 hours, two peaks were observed on the HPLC spectrum. The first peak was assigned to the 2,4-D. The chromatogram area of the 2,4-D was decreased compared to the one before reaction, which indicated that 2,4-D was converted during the photocatalytic reaction. By 
comparing the retention time with standard reference compounds, the second peak was assigned to 2,4dichlorophenol (2,4-DCP), which is a common intermediate of 2,4-D degradation [13]. Hence, it could be inferred that during the photocatalytic degradation process, 2,4-D was first converted to the 2,4-DCP intermediate. Then, the 2,4-DCP intermediate was further mineralized to carbon dioxide and water (Scheme 1). Since 2,4-D is a chlorinated compound, $\mathrm{HCl}$ was also present as one of the mineralization products [13].

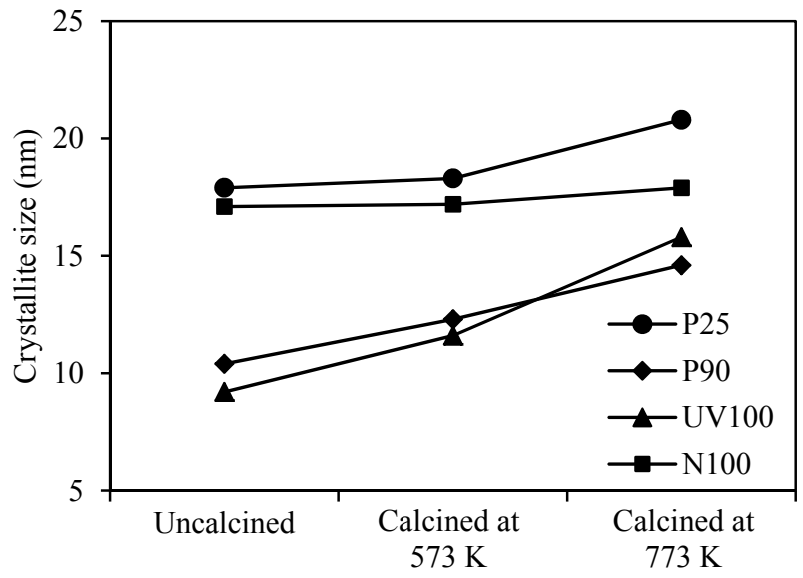

Fig. 1 Crystallite size of the uncalcined and calcined commercial $\mathrm{TiO}_{2}$ samples.

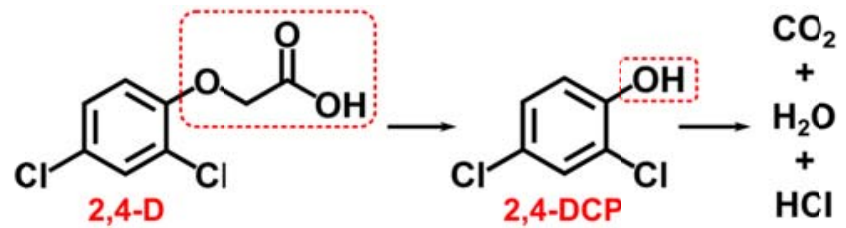

Scheme 1. The photocatalytic conversion of 2,4-D to 2,4-DCP and to final products.

Figure 2 shows the photocatalytic degradation activity of the four types of commercial $\mathrm{TiO}_{2}$ before and after calcination at 573 and $773 \mathrm{~K}$. The percentage of degradation was determined by the equation (1) shown previously. This calculation takes into account of the overall photocatalytic performance of the catalysts, which includes the degradation of both 2,4-D and 2,4-DCP. Before the calcination treatments, the P25 and P90 display similar activity, which was much higher than UV100 and N100. After calcination treatment at 573 and $773 \mathrm{~K}$, the photocatalytic activity of P25 and P90 were reduced. On the other hand, the calcination at 573 and $773 \mathrm{~K}$ led to an increase of photocatalytic activity of UV100 and N100.

It has been revealed that the P25 and the P90 have a mixture of anatase-rutile phase, while the UV100 and the N100 only have anatase phase [14]. This main difference caused the P25 and the P90 to have higher photocatalytic activity than the UV100 and the N100. The mixture of anatase and rutile phase would lead to a synergistic electron transfer that improved the charge separation of the photogenerated electron-hole pairs [15-18]. This in turn caused the improved photocatalytic activity of the P25 and the P90 $\mathrm{TiO}_{2}$ as compared to UV100 and N100.

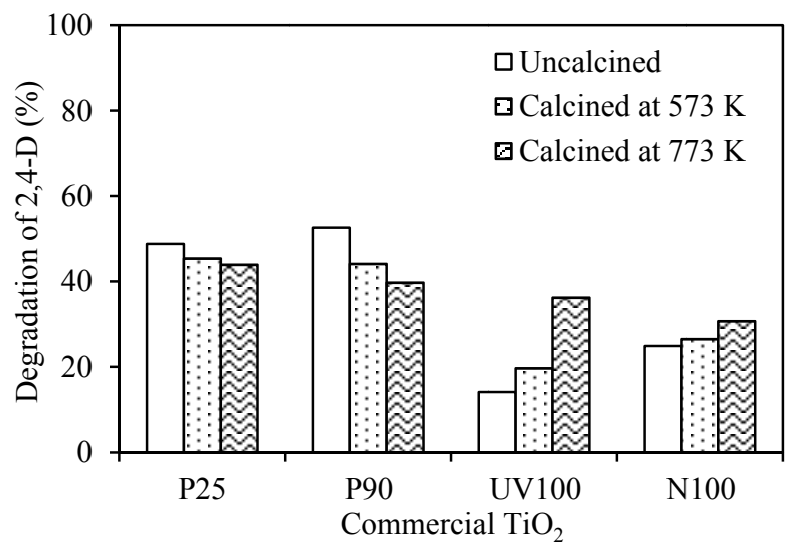

Fig. 2 The photocatalytic activity of the uncalcined and calcined commercial $\mathrm{TiO}_{2}$ for the degradation of 2,4-D.

The calcination treatment affected the activity of the commercial $\mathrm{TiO}_{2}$ photocatalysts for degradation of 2,4-D. The UV100 and N100 $\mathrm{TiO}_{2}$ showed improved activity with the increased calcination temperature. It is worth noting here that the UV100 showed much higher activity after the calcination process. The marked improvement of photocatalytic activity of UV100 could be attributed to the increase of its crystallinity, which resulted from the calcination treatment at 573 and $773 \mathrm{~K}$. By having higher crystallinity, the calcined UV100 also have fewer defect sites, and consequently longer lifetime of photogenerated electron-hole pairs [3, 8-10]. This in turn led to an increase in the photocatalytic activity of the calcined UV100. In comparison to UV100, the N100 only showed a small improvement of catalytic activity after calcination at 573 and $773 \mathrm{~K}$. This is understandable, considering the relatively high initial crystallinity of N100, which was not easily affected by the moderate temperatures used at the present calcination treatments. Hence, the slight increase in the activity of N100 with the increase of calcination temperatures would be due to the slight increase in the crystallinity.

In the case of P25 and P90, the activity was slightly decreased after calcination at $573 \mathrm{~K}$, and then it was decreased further after calcination at $773 \mathrm{~K}$. Based on the photocatalytic performances of the UV100 and N100, it was expected that there would also be an increase in the photocatalytic activity of P25 and P90 when calcined at 573 and $773 \mathrm{~K}$, due to the calcination induced crystallinity gain. However, the same reason could not be applied for P25 and P90 as the activity decreased after calcination treatment at 573 and $773 \mathrm{~K}$. Apart from resulting in an increase of crystallinity, the calcination process could also modify the nature of the active sites present on the surface of the $\mathrm{TiO}_{2}$ catalysts. For instance, surface hydroxyl groups on the surface of $\mathrm{TiO}_{2}$ play a vital role in a variety of 
photocatalytic reactions over $\mathrm{TiO}_{2}$ [6] as they act as efficient trapping sites for photogenerated holes, this in turn improves the charge separation of the electron-hole pairs. According to previously reported differential scanning calorimetry (DSC) study of P25, heating at temperatures 483-683 K led to the removal of surface hydroxyl groups [6]. Hence, calcination treatment of P25 and P90 at 573 and $773 \mathrm{~K}$ likely led to a gradual elimination of hydroxyl groups that was probably not restored on contact with water, remaining quasi permanent. The decreased activity could be due to the changing of surface structure related to the decrease of surface bound $\mathrm{OH}$ groups and it appears that in this case, it could not be compensated with the slight increase in the crystallinity of $\mathrm{P} 25$ and $\mathrm{P} 90 \quad \mathrm{TiO}_{2}$ $[4,5,7,9,10,19]$.

Further understanding on the photocatalytic performance of the samples could be obtained by considering the percentage of removal of 2,4-D after $3 \mathrm{~h}$ solar simulator irradiation. The percentage removal of 2,4$D$ was determined by equation (2) stated in the experimental section. This calculation only took into consideration of the amount of 2,4-D removed, not the amount of 2,4-DCP formed.

Figure 3 shows the percentage removal of 2,4-D for all commercial $\mathrm{TiO}_{2}$ samples before and after calcination treatments. After solar simulator irradiation for 3 hours, the P25 and P90 catalysts removed more than 95\% of 2,4-D, indicating that conversion from $2,4-\mathrm{D}$ to $2,4-\mathrm{DCP}$ is a very fast process, in comparison to the subsequent mineralization of 2,4-DCP. The UV100 and N100 catalysts also achieved a very high degree of 2,4-D removal of around $60 \%$ and above, further confirming the facile conversion from 2,4-D to 2,4-DCP.

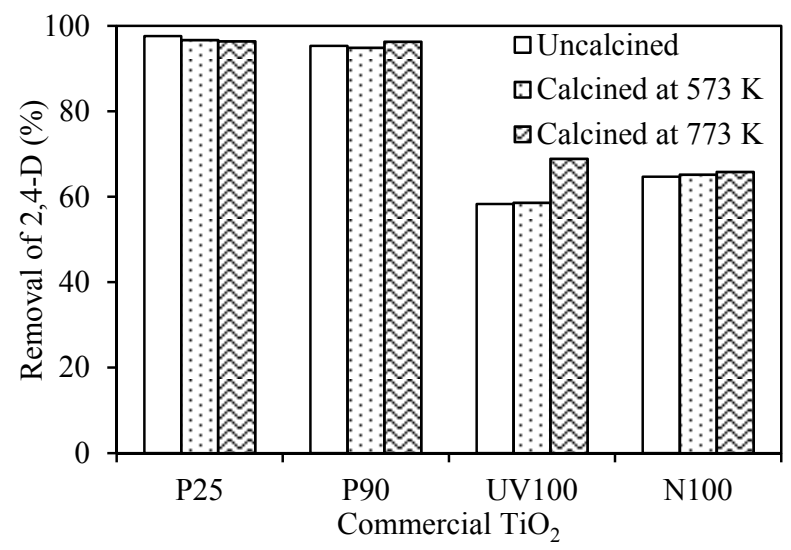

Fig. 3 The photocatalytic activity of the uncalcined and calcined commercial $\mathrm{TiO}_{2}$ for the removal of 2,4-D.

Some of the major catalytic activity trends observed in the degradation results (Figure 2) are also present in the removal results (Figure 3). Namely, the P25 and P90 samples are more photocatalytically active than the UV100 and N100 samples. Secondly, the more crystalline N100 samples display higher catalytic activity than the less crystalline UV100 samples. Thirdly, calcination heat treatment at 573 and $773 \mathrm{~K}$ led to an increase of photocatalytic activity of the UV100 and N100 samples.

\section{CONCLUSION}

In conclusion, the changes generated by the calcination treatment on the physicochemical properties of the unmodified $\mathrm{TiO}_{2}$ samples led to an increase of photocatalytic activity for Hombikat UV100 and Hombikat N100 and a decrease of photocatalytic activity for P25 and P90 $\mathrm{TiO}_{2}$. Among the investigated commercial $\mathrm{TiO}_{2}$, uncalcined P25 and P90 were the most active photocatalysts for the degradation of 2,4-D. Based on the photocatalytic activity results, no calcination treatment should be applied for P25 and P90 in order to preserve their high activity, while larger temperature range (573-773 K) could be used for UV100 and N100. These results are very crucial from the point of view of devising strategies for incorporating metal oxide co-catalysts on the surface of commercial $\mathrm{TiO}_{2}$, whereby the calcination treatment is often a standard procedure for metal oxide formation. Hence, the findings presented in this work serve to further enhance our understanding on the effect of heat treatments on selected commercial $\mathrm{TiO}_{2}$ samples.

\section{ACKNOWLEDGEMENTS}

The research leading to these results has received funding from the European Union Seventh Framework Program (EU-FP7) under 4G-PHOTOCAT grant (agreement no.: 309636). This work has been also financially supported by the Ministry of Higher Education (MOHE) and Universiti Teknologi Malaysia (UTM, Malaysia) through the international contract matching grant (cost center code: R.J130000.7626.4C035).

\section{REFERENCES}

[1] U.I. Gaya, A.H. Abdullah, J. Photochem. Photobiol. C 9 (2008) 1.

[2] C.M. Teh, A.R. Mohamed, J. Alloys Compd. 509 (2011) 1648.

[3] J. Ryu, W. Choi, Environ. Sci. Technol. 42 (2007) 294.

[4] J. Kirchnerova, M.L. Herrera Cohen, C. Guy, D. Klvana, Appl. Catal. A 282 (2005) 321.

[5] G. Wang, L. Xu, J. Zhang, T. Yin, D. Han, Int. J. Photoenergy 2012 (2012) 1.

[6] N. Bowering, G.S. Walker, P.G. Harrison, Appl. Catal. B 62 (2006) 208.

[7] V. Collins-Martínez, A. López Ortiz, A. Aguilar Elguézabal, Int. J. Chem. React. Eng. 5 (2007) 1.

[8] X. Qin, L. Jing, G. Tian, Y. Qu, Y. Feng, J. Hazard. Mater. 172 (2009) 1168 .

[9] P. Du, J.A. Moulijn, G. Mul, J. Catal. 238 (2006) 342.

[10] J.T. Carneiro, T.J. Savenije, J.A. Moulijn, G. Mul, J. Phys. Chem. C 114 (2009) 327.

[11] S. Ahmed, M.G. Rasul, R. Brown, M.A. Hashib, J. Environ. Manage. 92 (2011) 311.

[12] S.P. Kamble, S.B. Sawant, V.G. Pangarkar, Chem. Eng. Res. Des 84 (2006) 355.

[13] K. Djebbar, A. Zertal, T. Sehili, Environ. Technol. 27 (2006) 1191

[14] W.R. Siah, H.O. Lintang, M. Shamsuddin, L. Yuliati, IOP series: Mater. Sci. Eng., accepted.

[15] T. Ohno, K. Sarukawa, K. Tokieda, M. Matsumura, J. Catal. 203 (2001) 82. 
[16] D.C. Hurum, A.G. Agrios, K.A. Gray, T. Rajh, M.C. Thurnauer, J. Phys. Chem. B 107 (2003) 4545.

[17] B. Sun, A.V. Vorontsov, P.G. Smirniotis, Langmuir 19 (2003) 3151.

[18] D.O. Scanlon, C.W. Dunnill, J. Buckeridge, S.A. Shevlin, A.J. Logsdail, S.M. Woodley, C.R.A. Catlow, M.J. Powell, R.G. Palgrave, I.P. Parkin, G.W. Watson, T.W. Keal, P. Sherwood, A. Walsh, A.A. Sokol, Nat. Mater. 12 (2013) 798.

[19] N. Bowering, D. Croston, P.G. Harrison, G.S. Walker, Int. J. Photoenergy 2007 (2007) 1. 